\title{
OPTIMIZATION OF EMULSIFYING EFFECTIVENESS OF PHYTOSTEROL IN MILK USING TWO-LEVEL FRACTIONAL FACTORIAL DESIGN
}

\author{
- Research paper - \\ Yunxia $\mathrm{HE}^{*}$, He CHEN*, Zhangteng $\mathrm{LEI}^{*}$, Jili CAO ${ }^{* * 1}$, Yuan TAN** \\ *School of Food and Biological Engineering, Shaanxi University of Science \& Technology, \\ Xi'an, 710021, China \\ **Xi'an Oriental Dairy Co., Ltd., Xi'an, 710027, China
}

\begin{abstract}
In this paper emulsifying effects of seven emulsifiers including Tween 80, Span 80, tripolyglycerol monostearate, sodium stearoyl lactylate, sucrose ester, soy lecithin and monoglyceride on phytosterol in milk were investigated using single factor test and fractional factorial design. The addition for seven emulsifiers were in the following concentrations: $0.1 \%, 0.2 \%, 0.3 \%, 0.4 \%, 0.5 \%$ and $0.6 \%$. The results revealed that tripolyglycerol monostearate, sucrose ester and monoglyceride had a significant emulsifying effect on phytosterol in milk, Tripolyglycerol monostearate showed a positive emulsifying effect on phytosterol in milk, while sucrose ester and monoglyceride exhibited a negative emulsifying effect on phytosterol in milk.
\end{abstract}

Keywords: emulsifier; phytosterol; single factor test; fractional factorial design; emulsifying effectiveness

\section{INTRODUCTION}

Phytosterols or plant sterols, which are known as "the key to life", are the natural active substances derived from plant. They are major components of plant cells, which are widely existed in the roots, stems, leaves, fruits and seeds of plants. The structure of phytosterols are very similar to that of cholesterol which is primary sterol in animals, and only the structure of the side chains is different (Garcia-Llatas et al, 2011; Moreau et al, 2002). It is generally believed that phytosterols extensively exists in the vegetable oil, grains and their by-products. (Lengyel et al, 2012; De et al, 2003; Jr 2002). There are a wide variety of phytosterols, and more than 200 kinds of phytosterols have been identified from the plant. In nature, there are two types of phytosterols, which are free and esterified, while the esterified phytosterols are more likely to be soluble in organic solvents, and the absorption and utilization rate is about 5 times higher than that of free type. Free type of phytosterols have been found in nuts and legumes, the most common including $\beta$-sitosterol, sitosterol, campesterol and stigmasterol (Lengyel et al, 2012). And whole grain food is given priority to with the esterification type of phytosterols (Poutanen et al, 2014), in common with sitosterol ferulic acid ester, stigmasterol ferulic acid ester, etc.

The main physiological functions of phytosterols include: (1) reducing the total cholesterol (Calpe-Berdiel et al, 2009) and low density lipoprotein cholesterol (Hallikainen et al, 2000; Liu 2007; Nissinen et al, 2002), preventing and treating cardiovascular diseases (Kendall et al., 2004); (2) scavenging free radicals, anti-lipid peroxidation, anti-cancer effect (Ju et al, 2004; Awad et al, 2000; Awad et al, 2001); (3) immune regulation; (4) anti-inflammatory effect (Okoli et al, 2004; Nashed et al, 2005; Choi et al, 2003; Beger et al, 2004), anti-viral activity, anti-osteoarthritic properties (Gabay et al, 2010), etc. Phytosterols are widely used in following areas: (1) functional foods (Marangoni et al, 2010; Gill et

${ }^{1}$ Corresponding author. E-Mail address: xiandfcj1@gmail.com 
al, 2008; Otaegui et al, 2010; Paniangvait et al, 1995) for the prevention and treatment of cardiovascular diseases; (2) as antioxidants because it was demonstrated that phytosterols have thermostability and anti-oxidative activities (Bertelli et al, 2009; Butt et al, 2009; Dutta 2004; Paixao et al, 2008); (3) as pharmaceuticals (Fernandes et al, 2007). Phytosterols are mainly used for the medicine which can reduce cholesterol and treat cancer, anti-inflammatory and anti-pyretic, and they are intermediates for the preparation of steroid medicine; (4) in cosmetics. Phytosterols have emulsifying property, and they have strong permeability to skin, thus which can be used as skin nutritional agent (Folmer, 2003); (5) phytosterols can be used as synthetic material for steroid hormone medicine.

Because phytosterols are fat-soluble substances and poorly soluble in water ( $\mathrm{Jr} 2007)$, it is difficult to add phytosterols uniformly to food, cosmetics and pharmaceuticals and other products, which limits their application and

\section{MATERIALS AND METHODS}

Materials: Phytosterol was supplied by Xi'an Oriental Dairy Co., Ltd (Xi'an, China). Seven emulsifiers including Tween 80, Sucrose ester, Tripolyglycerol monostearate, Sodium stearoyl lactylate, Span 80, Soy Lecithin and Monoglyceride were provided by LSB Biochemical Co., Ltd (Xi'an, China). Fresh milk was purchased from a local farm (Weiyang district, Xi'an, China).

Preparation of phytosterol in emulsified milk: A certain amount of emulsifier and $0.2 \mathrm{~g}$ of phytosterol were incorporated into a beaker containing $40 \mathrm{~mL}$ fresh milk. The sample was thoroughly stirred $(10000 \mathrm{r} / \mathrm{min})$ by a magnetic stirrer (Model 78-1, JinTan Zhengji Instruments Co., Ltd, Jiangsu, China). Then the measurement of emulsification $\mathrm{R}$ was performed.

Determination of emulsification R: The absorbance of the sample $\left(\mathrm{A}_{1}\right)$ mentioned above was measured at $678 \mathrm{~nm}$ after the sample was stirred by the magnetic stirrer for function. The emulsification process can improve the application of phytosterols and extend their application fields. The emulsifying mechanism of phytosterols has been studied. At present, the emulsifiers applied in phytosterol are following: (1) Sucrose ester, which is nonionic surfactant with weak surface activity and hydrophilic property; (2) Lecithin, it has weak surface activity and hydrophilic property; (3) Monoglyceride, it is oily or waxy and is difficult to dissolve in water and glycerin, but can be stable in hot water; (4) Compound emulsifier, which is composed of two or more surface active agents. Generally, the emulsifying effect of the compound emulsifier is better than that of the single emulsifier (Ling et al, 1995).

In this study, single factor test and fractional factorial design was employed to investigate the emulsifying effect of seven emulsifiers on the phytosterol in milk, and initially evaluated the several factors which had a significant effect on emulsification process.

$10 \mathrm{~min}$ at $70^{\circ} \mathrm{C}$. Then the sample was centrifuged at $3000 \mathrm{r} / \mathrm{min}$ for $10 \mathrm{~min}$, the absorbance of the sample $\left(\mathrm{A}_{2}\right)$ was measured at the same wavelength. The emulsification $R$ $\left(\mathrm{A}_{2} / \mathrm{A}_{1}\right)$ was used to estimate the emulsion stability of phytosterol in milk.

Fractional factorial design: Seven emulsifiers including Tween 80, Span 80, Tripolyglycerol monostearate, Sodium stearoyl lactylate, Sucrose ester, Soy Lecithin and monoglyceride were incorporated to fresh milk. The addition of emulsifiers was for all: $0.10 \%, 0.20 \%$, $0.30 \%, 0.40 \%, 0.50 \%$ and $0.60 \%$. Phytosterol $0.5 \%(\mathrm{w} / \mathrm{v})$ mixed with milk mentioned above and was agitated at $70^{\circ} \mathrm{C}$ for $10 \mathrm{~min}$ by the magnetic stirrer.

According to the result of single factor test, a two-level fractional factorial design (FFD) was used to study the effect of these seven variables on the emulsification. The coded values of different levels (a high (+1) and a low level (-1) of each variable and their real values are shown in Table 1. 
Table 1. Independent variables and their coded levels in fractional factorial design

\begin{tabular}{|c|c|c|c|}
\hline \multirow{2}{*}{ Symbols } & Emulsifiers & \multicolumn{2}{|c|}{ Level } \\
\cline { 3 - 4 } & & -1 & +1 \\
\hline X1 & Tween 80 (\%) & 0.6 & 0.75 \\
\hline X2 & Sucrose ester (\%) & 0.5 & 0.625 \\
\hline X3 & $\begin{array}{c}\text { Tripolyglycerol } \\
\text { monostearate (\%) }\end{array}$ & 0.4 & 0.5 \\
\hline X4 & $\begin{array}{c}\text { Sodium stearoyl } \\
\text { lactylate (\%) }\end{array}$ & 0.4 & 0.5 \\
\hline X5 & Span 80 (\%) & 0.4 & 0.5 \\
\hline X6 & Soy Lecithin (\%) & 0.5 & 0.625 \\
\hline X7 & Monoglyceride (\%) & 0.2 & 0.25 \\
\hline
\end{tabular}

\section{RESULTS AND DISCUSSIONS}

\section{Effect of seven emulsifiers on emulsification $R$ of phytosterol milk}

As exhibited in Figure 1, different emulsifiers showed various effects on the emulsification $R$ at the same amount of addition. When the concentration of emulsifiers was $0.1 \%, 0.2 \%$ and $0.3 \%$, respectively, Span 80 had a significant effect on the emulsifying effectiveness of phytosterol in milk. When the concentration of emulsifiers was $0.4 \%$, Tripolyglycerol monostearate had a significant effect on the emulsification $\mathrm{R}$. While the concentration of emulsifiers was $0.5 \%$, Sucrose
The two-level FFD is shown in Table 2 where it can be seen that the effect of seven variables was investigated in 16 independent experimental runs. The effect of seven variables on the emulsification $R$ was evaluated.

Statistical analysis of the data: The statistical analysis was performed by the Minitab (Version 16.1.0) to identify the significant factors and their corresponding coefficients. Thus, sum of squares, F-value and $p$-value were evaluated to analysis the emulsification $\mathrm{R}$ of each trial.

ester had a markedly significant effect on the emulsification $\mathrm{R}$. When the concentration of emulsifiers was $0.6 \%$, Tween 80 , Span 80 and Soy lecithin all had a significant effect on the emulsification R. Moreover, the maximum emulsification $\mathrm{R}$ of Tween 80, Span 80, Tripolyglycerol monostearate, Sodium stearoyl lactylate, Sucrose ester, Soy lecithin and monoglyceride were $0.989,0.993,0.994,0.989$, 0.997, 0.991 and 0.989, respectively. And the optimum concentrations of emulsifiers mentioned above were $0.6 \%, 0.4 \%, 0.4 \%$, $0.5 \%, 0.5 \% 0.5 \%$ and $0.2 \%$, respectively.

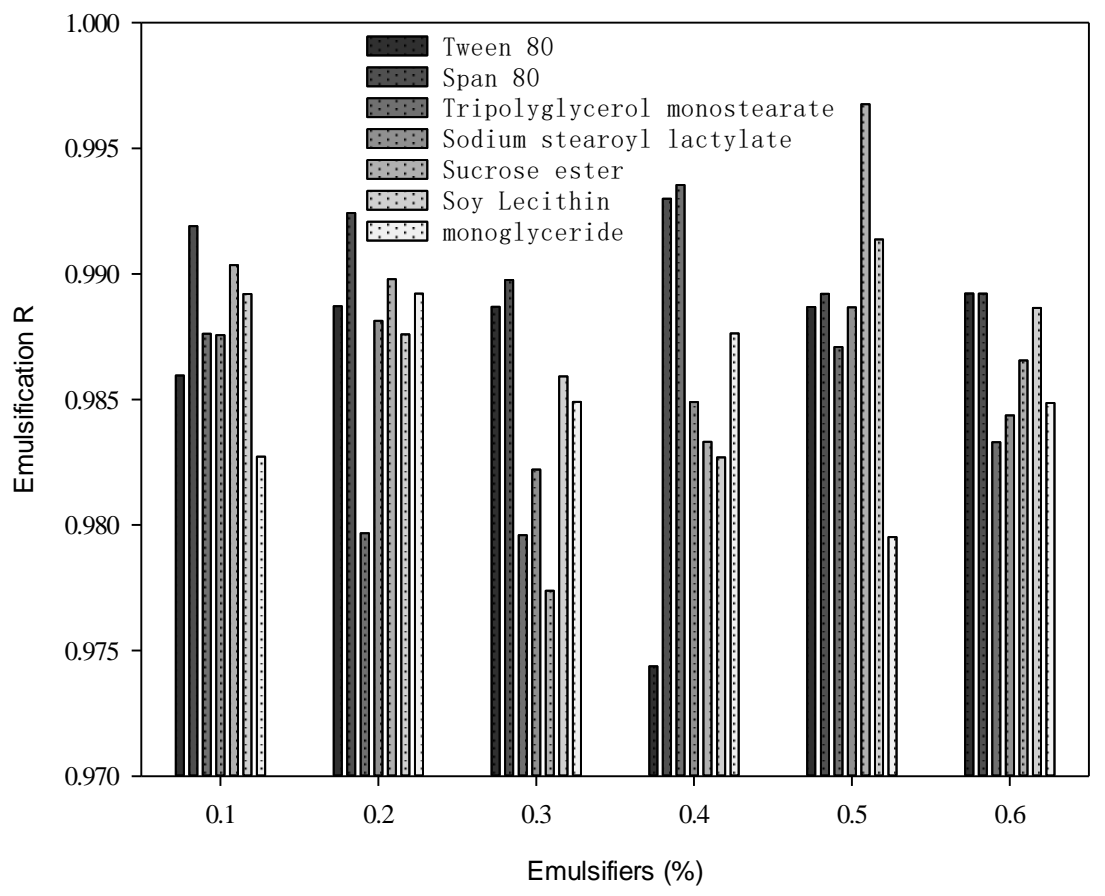

Figure1 Effect of seven emulsifiers on emulsifying effectiveness of phytosterol milk 
Screening of main factors affecting the emulsification of phytosterol in milk

Research has shown that the mixed emulsifier, which is compounded by two or more than two kinds of emulsifiers, which showed has a better effect than single emulsifier on emulsifying effectiveness (Ling et al, 1995). According to the results of the single factor test, main factors affecting the emulsification of phytosterol in milk were screened by using two-level fractional factorial design. In this study, 16 runs of experiments were conducted with 7 factors at two level. The two-level fractional factorial design and coded levels of each variable were exhibited in Table. 1. The experimental design and results of two-level fractional factorial were presented in Table. 2 . The response value of $\mathrm{R}$ was the emulsifying effectiveness of phytosterol in milk.

Table 2. The experimental design and results of fractional factorial design

\begin{tabular}{|c|c|c|c|c|c|c|c|c|}
\hline Run & $\mathrm{X} 1$ & $\mathrm{X} 2$ & $\mathrm{X} 3$ & $\mathrm{X} 4$ & $\mathrm{X} 5$ & $\mathrm{X} 6$ & $\mathrm{X} 7$ & $\mathrm{R}$ \\
\hline 1 & -1 & -1 & 1 & -1 & 1 & 1 & 1 & 0.9897 \\
\hline 2 & -1 & 1 & -1 & 1 & 1 & -1 & 1 & 0.9843 \\
\hline 3 & -1 & -1 & -1 & 1 & -1 & 1 & 1 & 0.9822 \\
\hline 4 & 1 & -1 & -1 & -1 & 1 & -1 & 1 & 0.9794 \\
\hline 5 & -1 & 1 & -1 & -1 & 1 & 1 & -1 & 0.9811 \\
\hline 6 & 1 & -1 & 1 & -1 & -1 & 1 & -1 & 0.9880 \\
\hline 7 & -1 & 1 & 1 & 1 & -1 & 1 & -1 & 0.9951 \\
\hline 8 & 1 & 1 & 1 & 1 & 1 & 1 & 1 & 0.9794 \\
\hline 9 & 1 & 1 & 1 & -1 & 1 & -1 & -1 & 0.9875 \\
\hline 10 & 1 & -1 & -1 & 1 & 1 & 1 & -1 & 0.9881 \\
\hline 11 & 1 & -1 & 1 & 1 & -1 & -1 & 1 & 0.9918 \\
\hline 12 & -1 & 1 & 1 & -1 & -1 & -1 & 1 & 0.9848 \\
\hline 13 & -1 & -1 & 1 & 1 & 1 & -1 & -1 & 0.9832 \\
\hline 14 & 1 & 1 & -1 & -1 & -1 & 1 & 1 & 0.9849 \\
\hline 15 & -1 & -1 & -1 & -1 & -1 & -1 & -1 & 0.9864 \\
\hline 16 & 1 & 1 & -1 & 1 & -1 & -1 & -1 & 0.9843 \\
\hline
\end{tabular}

The analysis of variance was performed by Minitab (Version 16.1.0) and the results were presented in Table 3. The significant factors and its contribution to emulsification of phytosterol in milk were shown in Figure 2. According to analysis of variance in the Table 3 , the model $p$-value of 0.0264 demonstrated the model was significant. $\mathrm{X} 2$ $(p$-value $=0.0431), \mathrm{X} 3(p$-value $=0.0051)$ and X7 $(p$-value $=0.0641) \quad$ showed a significant emulsifying effect on phytosterol in milk. And the significance rankings of those seven emulsifiers were: $\mathrm{X} 3>\mathrm{X} 2>\mathrm{X} 7>\mathrm{X} 5>\mathrm{X} 1>$ X4> X6. Meanwhile, Table 3 presented the coefficients of the regression equation for the response value $\mathrm{R}$, which illustrated that $\mathrm{X} 1, \mathrm{X} 3$ and X6 had a positive effect on the emulsification (R) of phytosterol in milk, namely that the response value emulsification (R) increased along with the addition of those three variable factors. And the rest four variables $\mathrm{X} 2, \mathrm{X} 4, \mathrm{X} 5, \mathrm{X} 7$ showed a negative correlation of the emulsification (R) of phytosterol in milk, namely that the response value (R) decreased as the increase of those four variables. As shown in Fig. 2, the contribution of these seven emulsifiers to the emulsification of phytosterol in milk, Monoglyceride (X7), Sucrose ester (X2) and Tripolyglycerol monostearate (X3) had a significant effect on emulsifying effectiveness of phytosterol in milk. In particular, X3 was the significant factor, the proportion of which reached more than $45 \%$ of all variables. 
Table 3. Analysis of variance (ANOVA) of experimental results of fractional factorial design

\begin{tabular}{|c|c|c|c|c|c|c|c|}
\hline Source & $\begin{array}{c}\text { Degrees } \\
\text { of } \\
\text { freedom }\end{array}$ & $\begin{array}{c}\text { Sum of } \\
\text { Squares }\end{array}$ & $\begin{array}{c}\text { Mean } \\
\text { Square }\end{array}$ & Coefficient & F Value & $\begin{array}{c}\text { p-value } \\
\text { (Probe>F) }\end{array}$ & $\begin{array}{c}\text { Significance } \\
\text { ranking }\end{array}$ \\
\hline Model & 7 & 0.00013 & $1.86 \mathrm{E}-05$ & & 4.4403 & 0.0264 & \\
\hline A-X1 & 1 & $7.6553 \mathrm{E}-06$ & $7.66 \mathrm{E}-06$ & 0.001383 & 1.8293 & 0.2132 & 5 \\
\hline B-X2 & 1 & $2.4136 \mathrm{E}-05$ & $2.41 \mathrm{E}-05$ & -0.00246 & 5.7678 & 0.0431 & 2 \\
\hline C-X3 & 1 & $6.1076 \mathrm{E}-05$ & $6.11 \mathrm{E}-05$ & 0.003908 & 14.5955 & 0.0051 & 1 \\
\hline D-X4 & 1 & $2.0883 \mathrm{E}-06$ & $2.09 \mathrm{E}-06$ & -0.00072 & 0.4990 & 0.5000 & 6 \\
\hline E-X5 & 1 & $1.0770 \mathrm{E}-05$ & $1.08 \mathrm{E}-05$ & -0.00164 & 2.5736 & 0.1473 & 4 \\
\hline F-X6 & 1 & $5.0653 \mathrm{E}-06$ & $5.07 \mathrm{E}-06$ & 0.001125 & 1.2104 & 0.3032 & 7 \\
\hline G-X7 & 1 & $1.9277 \mathrm{E}-05$ & $1.93 \mathrm{E}-05$ & -0.0022 & 4.6066 & 0.0641 & 3 \\
\hline
\end{tabular}

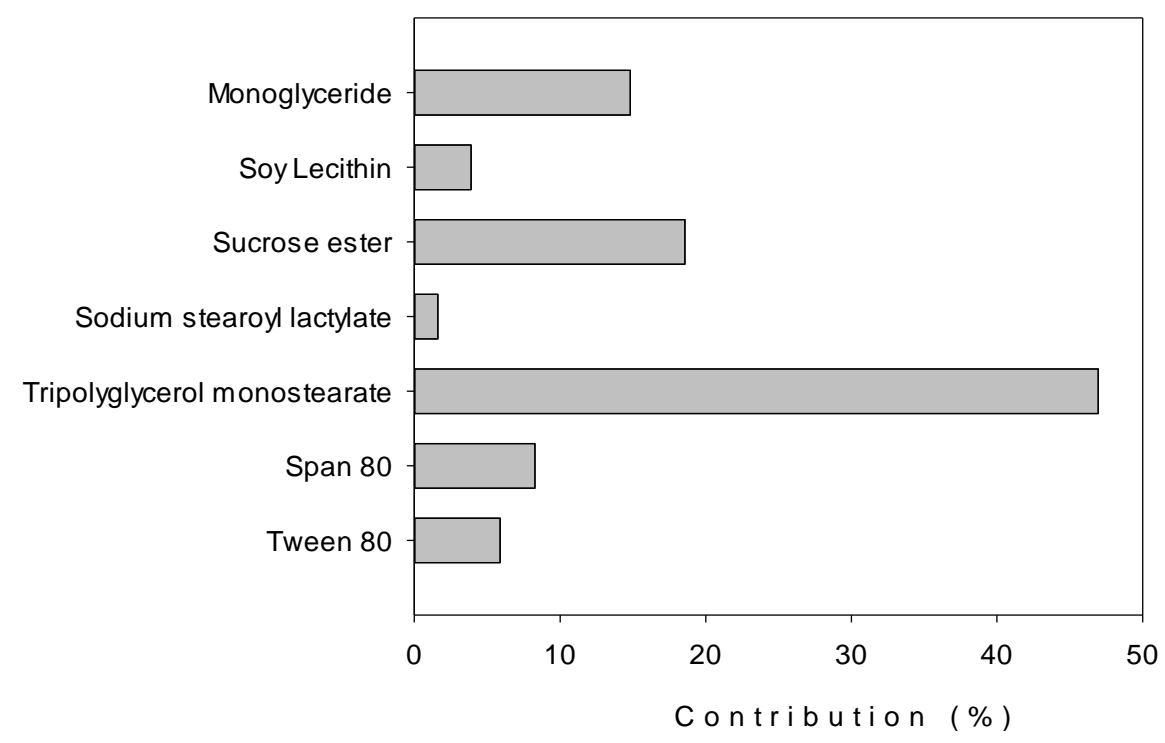

Figure 2. The contribution of seven emulsifiers to the emulsification of phytosterol in milk

\section{Discussion}

According to the results of single factor test, main factors affecting the emulsification of phytosterol in milk were screened by using two-level fractional factorial design. In the results of two-level fractional factorial design, X2 (Sucrose ester), X3 (Tripolyglycerol monosteareate) and X7 (Monoglyceride) had a significant effect on the emulsifying effectiveness of phytosterol in milk, and the $p$-value of the above-mentioned factors were $0.0431,0.0051$ and 0.0641 , respectively. In statistics, the confidence level was greater than $95 \%(0.01<\mathrm{p}<0.05)$, the factor was defined as a significant factor. While the confidence level was greater than $90 \%(0.05<\mathrm{p}<0.10)$, the factor was defined as an important factor. Thus, X2 (Sucrose ester) and X3 (Tripolyglycerol monostearate) were significant factors, $\mathrm{X} 7$ (Monoglyceride) was important factor, while there are few studies on the emulsifying process of phytosterol. Zhao et al (2009) optimized the emulsification system of phytosterols by orthogonal test, the result showed that the optimum emulsifier formulation was Span 60: Tween60: Sucrose ester $=41: 49: 10$. And in the study of Engel et al (2005), the result showed that the addition of Lecithin and Monoglyceride can inhibit the crystallization of phytosterol in water, so could improve the stability of phytosterol in aqueous solution. 


\section{CONCLUSIONS}

Based on the results of single factor test, two-level fractional factorial design was performed to study the emulsifying effect of seven emulsifiers on phytosterol in milk. The results showed that Sucrose ester (X2), Tripolyglycerol monostearate (X3) and Monoglyceride (X7) had a significant effect on emulsification of phytosterol in milk.

Among the above three factors, Sucrose ester and Tripolyglycerol monostearate were significant factors, and Monoglyceride was important factor.

Meanwhile, Tripolyglycerol monostearate had a positive effect on emulsification of phytosterol in milk, Sucrose ester and Monoglyceride had a negative effect on emulsification of phytosterol in milk. In addition, effect of those three factors on emulsifying effectiveness of phytosterol in milk: Tripolyglycerol monostearate (X3) > Sucrose ester (X2) > Monoglyceride (X7).

\section{ACKNOWLEDGEMENTS}

The work was partly supported by the science and technology project of $\mathrm{Xi}$ 'an city [2017050NC/NY007(1)], the Science and Technology Project of Xi'an City (No.XJR1506-(10)), and the Science and Technology Project of Baqiao District [No. 2016-(7)], China.

\section{REFERENCES}

1. Awad, A.B., Downie, A., Fink, C.S., et al. (2000). Dietary phytosterol inhibits the growth and metastasis of MDA-MB-231 human breast cancer cells grown in SCID mice. Anticancer Research, 20, 821-824.

2. Awad, A.B., Fink, C.S., Williams, H., et al. (2001). In vitro and in vivo (SCID mice) effects of phytosterols on the growth and dissemination of human prostate cancer PC-3 cells. European Journal of Cancer Prevention, 10, 507-513.

3. Beger, A., Jones, P.J.H., Abumweis, S.S. (2004). Plant sterols: factors affecting their efficacy and safety as functional food ingredients. Lipids in Health and Disease, 3, 5-23.

4. Bertelli, A.A., Das, D.K. (2009). Grapes, wines, resveratrol and heart health. Journal of Cardiovascular Pharmacology, 54, 468-476.

5. Butt, M.S., Sultan, M.T. (2009). Green tea: Nature's defense against malignancies. Critical Reviews in Food Science and Nutrition, 49, 463-473.

6. Calpe-Berdiel, L., Escola-Gil, J.C., Blanco-Vaca, F. (2009). New insights into the molecular actions of plant sterols and stanols in cholesterol metabolism. Atherosclerosis, 203, 18-31.

7. Choi, Y.H., Kong, K.R., Kim, Y.A., et al. (2003). Induction of Bax and activation of caspases during beta-sitosterol-meadiated apoptosis in human colon cancer cells. International Journal of Oncology, 23, 1657-1662.

8. De, J.A., Plat, J., Mensink, R.P. (2003). Metabolic effects of plant sterols and stanols. Journal of Nutritional Biochemistry, 14, 362-369.

9. Dutta, P.C. (2004). Chemistry, analysis, and occurrence of phytosterol oxidation products in food. In P. C. Dutta (Ed.), Phytosterols as functional food components and nutraceuticals (pp. 397-417). New York: Marcel Dekker Inc.

10. Engel, R., Schubert, H. (2005). Formulation of phytosterols in emulsions for increased dose response in functional foods. Innovative Food Science and Emerging Technologies, 6, 233-237.

11. Fernandes, P., Cabral, J.M.S. (2007). Phytosterols: applications and recovery methods, Bioresource Technology, 98, 2335-2350.

12. Folmer, B.M. (2003). Sterol surfactant: from synthesis to applications. Advances in Colloid and 
Interface Science, 103, 99-119.

13. Gabay, O., Sanchez, C., Salvat, C., et al. (2010). Stigmasterol: a phytosterol with potential antiosteoarthritic properties. Osteoarthritis and Cartilage, 18, 106-116.

14. Garcia-Llatas, G., Rodriguez-Estrada, M.T. (2011). Current and new insights on phy-tosterol oxides in plant sterol-enriched food. Chemistry and Physics of Lipids, 164, 607-624.

15. Gill, S., Chow, R., Brown, A.J. (2008). Sterol regulators of cholesterol homeostasis and beyond: The oxysterol 4 hypothesis revisited and revised. Progress in Lipid Research, 47, 391-404.

16. Hallikainen, M.A., Sarkkinen, E., Gylling, H., et al. (2000). Comparison of the effects of plant sterol ester and plant stanol ester-enriched margarines in lowering serum cholesterol concentrations in hypercholesterolaemic subjects on a low-fat diet. European Journal of Clinical Nutrition, 54, 715-725.

17. Jr, O.R. (2002). Phytosterols in human nutrition. Annual Review of Nutrition, 22, 533-549.

18. Jr, R.E.O. (2007). Phytosterols cholesterol absorption and healthy diets. Lipids, 42, 41-45.

19. Ju, Y.H., Clausen, L.M., Allred, K.F., et al. (2004). Beta-sitosterol, beta-sitosterol glucoside, and a mixture of beta-sitosterol and beta-sitosterol glucoside modulate the growth of estrogen-responsive breast cancer cells in vitro and in ovariectomized athymic mice. Journal of Nutrition, 134, 1145-1151.

20. Kendall, C.W., Jenkins, D.J. (2004). A dietary portfolio: maximal reduction of lowdensity lipoprotein cholesterol with diet. Current Atherosclerosis Reports, 6, 492-498.

21. Lengyel, J., Rimarcik, J., Vaganek, A., et al. (2012). Oxidation of sterols: energetics of C-H and O-H bond cleavage. Food Chemistry, 133, 1435-1440.

22. Ling, W.H., Jones, P. J. H. (1995). Dietary phytosterols: a review of metabolism, benefits and side effects. Life Sciences, 57(3), 195-206.

23. Liu, R.H. (2007). Whole grain phytochemicals and health. Journal of Cereal Science, 46, 207-219.

24. Marangoni, F., Poli, A. (2010). Review: phytosterols and cardiovascular health. Pharmaceutical Research, 61, 193-199.

25. Moreau, R.A., Whitaker, B.D., Hicks, K.B. (2002). Phytosterols, phytostanols, and their conjugates in foods: structural diversity, quantitative analysis, and health- promoting uses. Progress in Lipid Research, 41, 457-500.

26. Nashed, B., Yeganeh, B., Hayglass, K.T., et al. (2005). Antiatherogenic effects of dietary plant sterols are associated with inhibition of proinflammatory cytokine production in Apo E-KO mince. Journal of Nutrition, 135, 2438-2444.

27. Nissinen, M., Gylling, H., Vuoristo, M., et al. (2002). Micellar distribution of cholesterol and phytosterols after duodenal plant stanol ester infusion. American Journal of Physiology Gastrointestinal \& Liver Physiology, 282, 1009-1015.

28. Okoli, C.O., Akah, P.A. (2004). Mechanisms of the anti-inflammatory activity of the leaf extracts of Culcasia scandens P. Beauv (Araceae). Pharmacology Biochem and Behavior, 79, 473-481.

29. Otaegui-Arrazola, A., Menéndez-Carreño, M., Ansorena, D., et al. (2010). Oxysterols: a world to explore. Food \& Chemical Toxicology, 48, 3289-3303.

30. Paixão, N., Pereira, V., Marques, J.C., et al. (2008). Quantification of polyphenols with potential antioxidant properties in wines using reverse phase HPLC. Journal of Separation Science, 31, 2189-2198.

31. Paniangvait, P., King, A.J., Jones, A.D., et al. (1995). Cholesterol oxides in foods of animal origin. Journal of Food Sciences, 60, 1159-1174.

32. Poutanen, K., Sozer, N., Valle, G.D. (2014). How can technology help to deliver more of grain in cereal foods for a healthy diet? Journal of Cereal Science, 59, 327-336. 
33. Zhao, X., Hu, C.R., Chen, L.J. (2009). Optimization of the emulsification system of phytosterols. Food Science and Technology, 34(6), 234-236. 